\title{
BOEKBESPREKING
}

Dr. Melville J. Herskovits. 1. Man, the Speaking Animal, Aflevering van het 2de kwartaal van het tijdschrift $S . X$ (in grieksche letters: sigma xi) van de te Easton in Pennsylvania gevestigde afdeeling van het genootschap van dien naam, Deel 2I, no. 2, Juni I933, blz. 67-83. - 2. A Footnote to the History of Negro Slaving (in samenwerking met Mevr. F.S. Herskovits), Juni-aflevering 1933 van het tijdschrift Opportunity, Deel 9, blz. I78-I8I, $4^{\circ}$. - 3. On the Provenience of New World Negroes, December-aflevering I933 van het tijdschrift Social Forces, Deel I2, no. 2, blz. 247-263. - 4. An Outline of Dahomean Religious Belief (te zamen met Mevrouw Herskovits), Memoirs of the American Anthropological Association, no. 4I, I933, 77 bladz., 6 platen buiten den tekst. - 5. Aankondiging van vier boeken, uitgegeven door het Internationaal Instituut voor Afrikaansche talen en beschavingen, Journal of American Folklore, Deel 46, April-Juni I933, no. I80, blz. I9I195. - 6. Race Relations, The American Journal of Sociology, Deel 38, no. 6, Mei 1933, blz. 913-922.

Over deze zes geschriften van den zoo vruchtbaren, aan den lezer van De W.I. Gids welbekenden schrijver, wil ik het volgende zeggen. De enorme in de zes geschriften neergelegde arbeid is een resultaat van de door den heer en mevrouw Herskovits gedane onderzoekingsreizen bij de Boschnegers in Suriname, en van een reis in de binnenlanden van West-Afrika, waar zij tot in den Staat Kano doordrongen, en door den Emir van dat gebied werden ontvangen. Een uitvoerige bespreking zou slechts een geringe hulde zijn aan hetgeen beiden op het gebied van volkenkunde hebben verricht. Ik wil echter mijne aankondiging beperken tot 
die bijzonderheden en geschriften, die voor dit tijdschrift het meest van belang zijn.

No. 1 is eigenlijk slechts bestemd voor vaklieden, in de eerste plaats taalkundigen. $\mathrm{Zij}$ dienen zich (zoo betoogt de schrijver) er voor te behoeden om te spoedig europeesche oorsprongen in talen van andere werelddeelen aan te nemen. Het overkwam dr. $\mathrm{H}$.

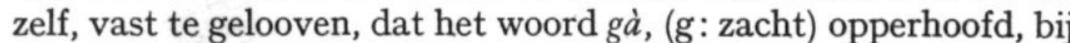
een Boschnegerstam in Suriname, afstamt van den SpaanschPortugeeschen wortel van grande, doch later, bij onderzoek van de Fong- en Ewetalen van volken in het hart van West-Afrika, van waar deze Boschnegers zijns inziens gekomen zijn, is hem gebleken, dat dáár het woord voor opperhoofd precies hetzelfde en zuiver afrikaansch is. De namen Jim Crow, en John Canoe (op Jamaica), worden nagenoeg op dezelfde wijze uitgesproken als de naam van de gier bij de Boschnegers in Suriname, welke zóózeer overeenkomt met het Ashantiwoord voor ,gier”, dat in dit geval het oorspronkelijke, afrikaansche woord, vermoedelijk op onherkenbare wijze in een europeesche taal is verbasterd. Onze letterteekens reiken vaak niet toe om de juiste uitspraak weer te geven. Eigenaardig dat iemand die honger heeft in het Surinaamsche negerengelsch zegt: Hangri kiri mi, honger doodt mij, maar dat de inwoner van Asjanti in dat geval een uitdrukking met dezelfde woordschikking bezigt, hoewel de Surinaamsche neger honderden jaren geleden van zijne verwanten in Afrika gescheiden werd. Het onderzoek naar taal-geschiedkundige aanrakingen blijft een moeilijk werk.

No. 2. De heer en mevrouw H. werden te Abomey, de hoofdstad van het koninkrijk Dahomé, in een auto naar een tempel gebracht en spraken met den hen vergezellenden tolk over heidensche vereering bij negers in Amerika, en de tolk was er, op grond van overeenkomst in geloof, van overtuigd, dat onder die negers afstammelingen van inwoners van Dahomé waren. Gedurende dit gesprek begon de neger-chauffeur steeds langzamer te rijden, om geen woord te missen en plotseling was er tusschen beide Afrikanen een levendige woordenwisseling, daarna een langdurige stilte. De chauffeur weent, zeide de tolk, de tranen die hij stort zijn eerbiedwaardig.

Eerst later kwamen de heer en mevr. H. van den chauffeur te hooren, waarom hij zoo ontroerd was geweest. Hij wist, door familieoverlevering, van voorouders die op slavenjachten waren weggesleept, maar nooit had hij vernomen waarheen zij waren gebracht. De Aguda (de Portugeezen) kochten ze op in het land Popo (nu Fransch Togo) en brachten ze vandaar naar het tegenwoordige Freetown. Daar was een negerdorp aangelegd, waar de 
Aguda bevorderden dat er kinderen kwamen, en die kinderen verkochten zij weer. (Ik meen, dat totnogtoe niet of weinig bekend is geworden, dat slavenhalers er een stelselmatige kinderfokkerij op nahielden. v. P.) De weggevoerde familieleden van den chauffeur werden nog steeds beschouwd als te behooren tot de familie, en wanneer er voor de dooden geofferd werd, werden ook hunne zielen opgeroepen om aan het offer deel te nemen. Daaruit volgt, - het blijkt uit het onderling verband - , dat er thans nog in Afrika geofferd en gebeden wordt voor de voorouders van voormalige slaven en van boschnegers in Suriname.

De dooden worden, zoo bleek aan Dr. H. en mevrouw bij nader onderzoek, bij offerfeesten opgeroepen o.a. uit Jovotomé, het land van de blanken, vroeger: Engeland maar thans Frankrijk; uit Am-ika (Amerika); uit Agudo tomé (Portugal); uit Blesi (Brazilië); uit Kpanyo (Spanje) en uit Kankanu, het land van de „Kankan”, de schitterenden, d. i. uit Nederland. (In ons artikel Boschnegers, in de Encyclopaedie van Ned. West-Indië zal men iets over de afleiding van het woord „Kankan” vinden).

No. 3. In een noot staat, dat door de American Folk-Lore Society een boekdeel zal worden uitgegeven getiteld "Suriname. Folk-Lore", door den heer en mevr. Herskovits. Zooals te begrijpen is stelt dr. H. vast, dat aan de kennis van de afkomst van de negers in de Nieuwe wereld de studie van hunne beschaving tot. grondslag zal moeten dienen. Bij het onderzoek zullen de geschiedenis en de volkenkunde in onderling en nauw verband met elkander moeten samenwerken. Onder de bronnen worden genoemd de beschrijving van W. Bosman, van de kust van Guinee; het bekende boek van Mr. J. J. Hartsinck over Suriname, en Ollendorps geschiedenis van de Herrnhutter zending op S. Thomas, S. Croix en S. Jan, waarvan een gedeelte, blz. 270 tot 444 van de uitgaaf van 1777 waardevolle gegevens bevat over de negers van die drie eilanden. O. noemt o.a. als volk de Kanga, waarvan de naam als een nog in Suriname in zwang zijnden dans voorkomt in ons opstel in dit tijdschrift over Surinaamsche folklore. Overziet men de beschikbare bronnen dan komt men tot de slotsom, dat de grenzen van het deel van Afrika, vanwaar de slaven kwamen, veel nauwer moeten worden getrokken dan totnogtoe werd geloofd en aangenomen. De duur van de reis naar de kust (tot twee jaar in Kano) kon o.a. oorzaak hebben in groote omwegen om vijandelijk grondgebied te mijden.

De Surinaamsche boschnegers leveren de meest waardevolle gegevens voor het onderzoek dat dr. $\mathrm{H}$. bedoelt, want zij vertegenwoordigen een oude, voormalige, West-Afrikaansche be- 
schaving, die in de afzondering van de Surinaamsche wouden bijna volkomen onveranderd bleef, terwijl de verwante beschavingen in Afrika zich verder ontwikkelden door inwendige oorzaken en cultureele aanrakingen van buiten. Dr. H. geeft voorbeelden van overeenkomst. Een boschneger zeide hem: Ik ben een man uit Asjanti; boschnegerdorpen heeten: naar den oude Koninklijke Asjantijnschen naam: pempeh, naar Dahomé, naar Lome in Togo, naar de Soedaneesche stad Malobi, naar Godo in Dahomé. Een stam draagt den naam van „Loango”, een ander: „Anago”, naar het Nago-volk van Joruba.De Asjanti-val voor klein wild, mo, heet nog zoo bij de boschnegers. Het persoonlijke voedsel-taboe (verbod) draagt bij de boschnegers den Loango-naam van tschina. De wijze van tatouage en de patronen zijn als die van Dahomé. De Aarde-moeder heet, als bij de Fanti en Asjanti, Asasé; deze opmerking geeft ons de verklaring van de beteekenis van het woord Ma Asan (Ma-Asâ) in een van de doodenliedjes, in ons aangehaald opstel over Surinaamsche folklore. Leba, Gedeonsoe, de Dagowé-slang, Aisa en Loko, Ewe-goden, worden bij de boschnegers op dezelfde wijze geëerd als in Afrika. De apintitrom, in de geheime kromanti-taal: Asante-Kwogba, Asjanti-Kwogbageheeten, heet ook in Nigeria apinti. De schildpadheeft bij den boschneger den Ewe-naam van logozo (een naam dien wij ook omstreeks 1893 bij de Djoeka's te Albina noteerden). Zoo gaat de lijst door.

Voor Jamaica zijn vele gegevens van nut voor de studie van dr. H.'s onderwerp te vinden in een aldaar in 1929 te Chapel Kill uitgekomen boek van Martha Beckwith, met den titel: Black Roadways, a Study of Jamaican Folk Life. Op dat eiland is, evenals in Suriname, op Curaçao en op de Virginische eilanden, Anansi, van de Afrikaansche Goudkust de held in de dierfabels. De tradities van de negers op Cuba komen met die in Brazilië overeen. OpHaïti heet een kind dat na tweelingen geboren wordt, evenals in Suriname, dosu. Codjo, Cuffy en Quashie (neger-namen in Suriname) worden ook gevonden bij negers in het zuiden van de Vereenigde Staten.

No. $4-6$. Op het uitvoerige opstel over godsdienstig geloof in Dahomé gaan wij niet nader in. Ook het onder no. 6 vermelde artikel laten wij hier onbesproken. Uit de boekaankondiging bedoeld onder no. 5 blijkt, dat het Internationaal Instituut voor Afrikaansche talen en beschavingen niet alleen het tijdschrift „Africa" uitgeeft; maar ook een serie van werken en memoranda. In een aangekondigd boek van A. W. Cardinal, Tales told in Togoland, Oxford University Press, London, H. Milford, 1931 komt een verhaal voor hoe Anansi een spin werd.

L. C. VAN PANHUYS 


\section{BATAKS EN BATAKS}

Dr. T. S. G. Moelia. Het primitieve denken in de moderne wetenschap. (Wolters, Gron. Den Haag, Batav. 1933).

De verkorte inhouds-opgaaf ziet er aldus uit: I. het primitieve denken in de philosophie; in de ethnologie; in de Völker- en ontwikkelings-psychologie; in andere takken van wetenschap. II. De theorie van Lévy-Bruhl en zijn aanhangers. III. Onderzoekingen omtrent het primitieve denken. IV. Primitieve logica. V. Het wezen van het primitieve denken.

„Is het vooral de ethnologie die zich met de geestesgesteldheid der volken op een lageren trap van beschaving bezighoudt, ook andere wetenschappen hebben de psychische verschijnselen, zooals deze zich bij de natuurvolken openbaren binnen haar gebied getrokken. Langs dezen weg tracht de psychologie een dieper inzicht te verkrijgen in de algemeene structuur van de menschelijke psyche en tevens daarin steun te zoeken voor de verklaring van hypothesen met betrekking tot de geestelijke afwijkingen. De geesteswetenschappen hopen door haar belangstelling vergelijkings-materiaal te vinden voor het beter verstaan van de historische ontwikkeling van den menschelijken geest zooals zij spreekt uit godsdienst, moraal, taal, recht en kunst.

„In de laatste instantie zijn de verschijnselen waarmede de ethnologie zich bezighoudt, terug te voeren tot psychologische processen. Daarom kan de psychologie worden beschouwd als een noodzakelijke hulpwetenschap van de ethnologie. In ieder geval mag tusschen beide takken van wetenschap een verband worden gelegd in dezen zin, dat bij het zelfstandig onderzoek door de ethnologie naar de psychische uitingen van den natuurmensch zij daarbij zooveel mogelijk dient gebruik te maken van deugdelijk bevonden psychologische methoden en haar uitkomsten vergelijkt".... hier en in de volgende alinea ontvliedt de schrijver mij. Dan verder: „Deze studie is (dus) niet opgezet met een praktisch doel, zoodat zij niet de pretentie heeft om daarin praktische wenken te geven. $\mathrm{Zij}$ moge haar rechtvaardiging alleen vinden in de door den schr. gevoelde noodzakelijkheid van een critisch systematische verwerking van het zeer uitgebreide en uiteenloopende materiaal, dat zich met dit vraagstuk hetzij rechtstreeks hetzij zijdelings bezighoudt, daarbij steunende op de eigen waarneming van den schrijver...." En nu komt de groote ver- 
rassing.... „die tot de Bataks behoort, een volk, dat voor eenige decennia nog in het stadium van de primitieve natuurvolken verkeerde".

Uit de Encyclopaedie van N. Indië en in het Museum te Rotterdam putte ik mijn kennis van de Bataklanden en de Bataks. Zie hier wat het Museum-gidsje (58ste duizend, 1929, bl. 29 en 30) van deze afdeeling der verzameling zegt:

„Het kannibalisme kwam voor bij de Bataks; door aanraking met anderen hebben zij tal van eigenaardigheden, die hen belangrijk maakten, verloren. Een eigen letterschrift bezaten zij lang voor de komst der Europeanen. Hindoesche invloed is merkbaar. Weefcentrum van den eersten rang, doch nu snel verbasterend. Antiek kralenwerk en gietwerk; houten en steenen beeldjes, amuletten, tal van wichelboeken en wichel-tabletten van beenen platen, dikwijls tot gordels saamgevoegd, dienende tot het bepalen van omineuze tijdstippen; potjes voor tooverbrij voornamelijk uit menschelijke lichaamsdeelen bereid. Oorsieraden van Toba, Silindoeng, kleeding van Pakanten; met Bataksch schrift beschreven bamboe-geledingen uit dezelfde streek.

„Bijzonder vlechtwerk. Tooverstokken, met aaneen gesneden menschen- en dierenfiguren, maskers voor ceremonieele dansen, schaakspel, dobbelsteenen. Statige palmwijnkokers van bamboe, veel kleinere bamboekokers met subtiele graveering versierd. Bamboe-lepels, die ondanks de volslagen algemeenheid en gelijkheid van het materiaal over den geheelen Archipel, in dien vorm niet voorkomen. Serie kogelhouders van hoorn en hout, met menschen-maskers, die in strengheid van stijl voor de beste westersche plastiek niet onderdoen. In dit opzicht munten ook uit de bewerkte zwaarden. Merkwaardige muziek-instrumenten, katjapi en seroenai".

Ziedaar wat het land van dr. Moelia voor een museum oplevert.

Eenige dagen na de ontvangst van het boek, ben ik uitgegaan „met den verneemstok”. In Leiden zou men wel meer ervan weten en uit Leiden kreeg ik spoedig een vriendelijk briefje, „Moelia is geen mythe, maar een heusche Batakker, zij 't dan ook Christen gedoopt en West-Europeesch gekleed. Ik heb hem gekend, berichtte de briefschrijver, in 1916/17; hij was toen, geloof ik, onderwijzer en studeerde nog verder, waarschijnlijk voor de hoofdacte. Hij was een protégé van prof. Van Ophuysen en woonde als ik 't wèl heb, ook in zijn huis. Ik heb in dien tijd bij prof. van Ophuysen (tot zijn dood in begin 1917) college geloopen in Bataksch, en Moelia zat daar ook bij. Sedert heb ik Moelia niet 
meer teruggezien, maar hij heeft, hoor ik, een voorspoedige carrière gehad bij het onderwijs in Indië, en is ook lid geweest van den Volksraad. Van zijn promotie hoorde ik pas naderhand; hij is den dag na de plechtigheid weer naar Indië vertrokken".

Van Moelia bezit ik geen portret; zooals uit het bovenschrift blijkt is dat van zijn landgenoot afkomstig uit het Museum te Rotterdam, waar het aan de kas wordt verkocht.

„In de kleeding, schrijft prof. Jonker (Encycl. v. N.I. I 1917 bl. 178a) doet zich hoe langer hoe meer vreemde, zoowel Westersche als Maleische invloed gevoelen; vooral geldt dit de kleeding der mannen. In het Karo-en in het Tobaland gaan ook vele mannen nog gekleed op zijn Bataksch; hetzij in eigengemaakte weefsels, hetzij in Europeesche wit katoenen stof, die de vrouwen met indigo verven. Hoofdbestanddeel van de kleeding is het lange om de lendenen geslagen en tot op de voeten afhangende kleed (abit, gondjé). In het Karoland dragen zoowel de mannen als de vrouwen in den regel een hoofddoek resp. boelang en toedoeng geheeten; in Toba loopen de vrouwen veelal met het bloote hoofd. Verschillende baadjes komen hoe langer hoe meer in zwang. Toch worden ze nog niet algemeen gedragen. Ter bedekking van het bovenlijf volstaat men nog dikwijls met een eenvoudigen omslagdoek".

Het volgende is ontleend aan dr. Moelia's vijfde hoofdstuk „Het wezen van het primitieve denken”. (Zie ook „Zielen in soorten"; dit tijdschrift Feb. 1934).

"Op geen ander gebied openbaart zich de begrensdheid van den menschelijken geest, die op het terrein van wetenschap en techniek zooveel veroveringen maakt, als juist in de studie van de eigen ziel. De menschelijke ziel in haar diepste roerselen, de geest in zijn duizelingwekkende concepties, maar niet minder de instincten in de uitleving van de laagste hartstochten plaatsen de wetenschap nog steeds voor onopgeloste raadsels.

„Geldt dit reeds voor de ziel van den Westerschen mensch, die door psychologie, psychopathologie en psychiatrie tot object van studie is gemaakt, hoeveel te meer moet tegenover de psyche der primitieven, die zoo ver van den cultuurmensch staat, de noodige schroom en reserve in acht worden genomen. De Westersche onderzoeker met zijn geheel andere geestesinstelling kan zich niet dan met zeer veel moeite, als hem dit tenminste ooit zal lukken, toegang verschaffen tot de psyche der primitieven. 
„Deze op hun beurt kunnen zich niet op het niveau van den onderzoeker plaatsen om zijn bedoelingen te begrijpen, zijn daardoor achterdochtig en laten zich òf intimideeren òf suggereeren, met het gevolg dat van het geestesleven der primitieven niet zelden een onbetrouwbaar, zelfs soms een misleidend beeld wordt gegeven. Rekening houdende met de onvolkomenheid van onze psychologische methoden en de betrekkelijkheid onzer kennis omtrent de algemeene organisatie van de menschelijke ziel eenerzijds, anderzijds met de moeilijke toegankelijkheid van de primitieve ziel voor onze Westersche onderzoekingsmethoden, dan is het duidelijk, dat wij met betrekking tot het primitieve denken, als geestelijke functie van de primitieve psyche, in onze studie slechts mogen spreken van benadering. Een scherpe omlijning van het wezen van de primitieve psyche is naar onze meening niet te geven, evenmin als zulks van de ziel van den modernen mensch mogelijk is. Ook hier moeten wij alleen volstaan met het aangeven van de karakteristiek en de hoofdkenmerken van het beeld, dat de primitieve psyche in al haar menschelijkheid aan ons toont. Wij kunnen ze op onze wijze verstaan, zinvol opvatten, haar structuur opstellen enz., tot het wezen van de menschelijke psyche vermogen wij niet door te dringen evenmin als tot het wezar var so nhyzsisshe strustuur van atonm of electron.

„,De oude philosophie en de speculatieve psychologie hielden zich uitsluitend bezig met vragen, omtrent het wezen der ziel. Het ging haar niet om het kennen van den mensch in zijn levensuitingen, maar om de metaphysica van het zielsgebeuren. De nieuwere psychologie zet de menschelijke persoonlijkheid op den voorgrond; zij zoekt niet meer naar kwantificeering van het psychische leven, ook niet in de eerste plaats naar zijn verklaring, maar wenscht allereerst te verstaan en te begrijpen. Ze richt zich van het kwantitatieve naar het kwalitatieve, van de elementaire functies tot de totale persoonlijkheid, van het objectieve „Ichindifferente" naar het subjectieve „Ich-bezogene”.

„Het overbrengen van deze phaenomenologische methode op de primitieven gaat echter met groote moeilijkheden gepaard. Zelfs voor de Westersche ziel eischt beschrijving van de doorleving en aanvoeling van de psychische phaenomenen in hun kwalitatieve geaardheid diepe menschenkennis, intuitie en scholing, eigenschappen, die niet iedereen gegeven zijn.

,En in de moderne samenleving staan onderzoeker en onderzochte nog in het algemeen op hetzelfde cultureel niveau, terwijl den Westerschen onderzoeker tegenover de primitieven, bijna 
ETHNOLOGISCH EN MARITIEM MUSEUM TE ROTTERDAM

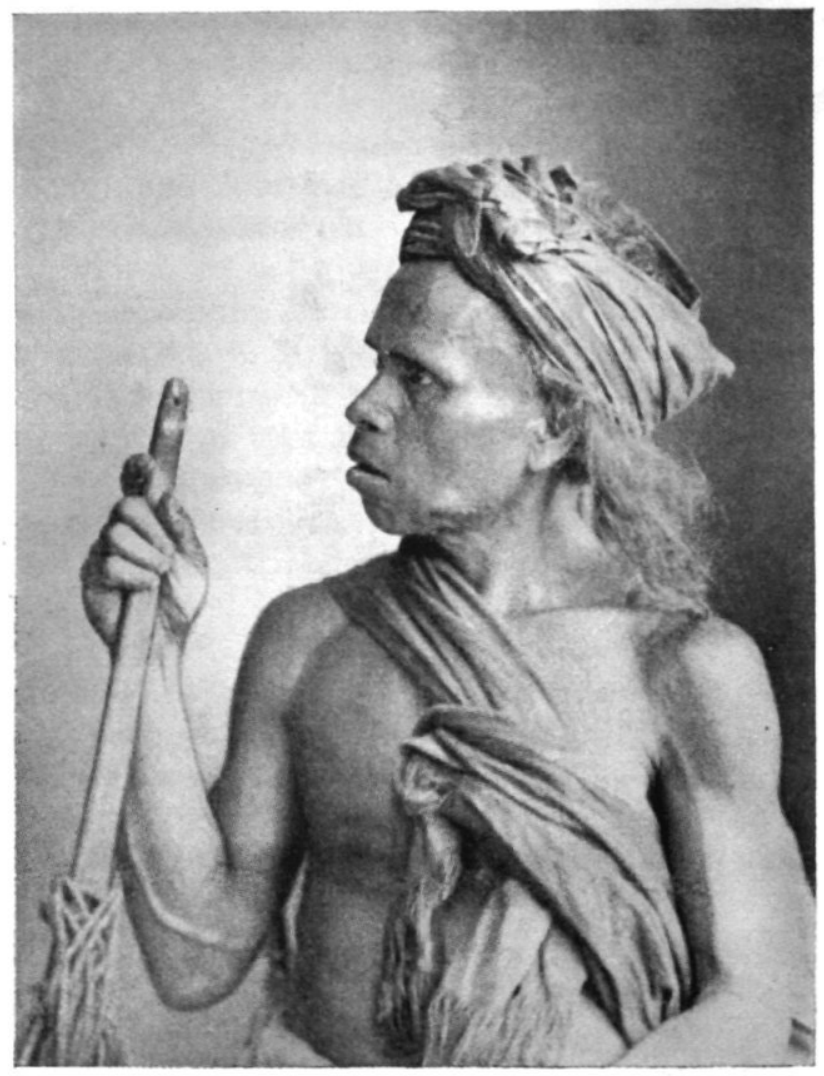

Batak-man, Sumatra 